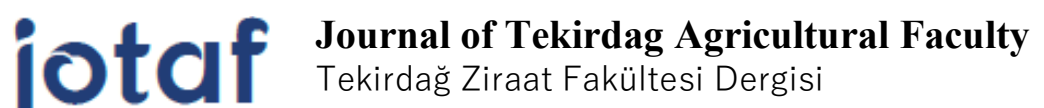

\section{Parlak Brom (Bromus catharticus Vahl.) Hatlarmın Ot Verimi ve Bazı Morfolojik Özelliklerinin Belirlenmesi*}

Determination of Forage Yield and Some Morphological Characteristics of Prairie Grass (Bromus catharticus Vahl.) Lines

\author{
Ersan BATO ${ }^{1^{*}}, \quad$ Illker NIZAMM ${ }^{2}, \quad$ Metin TUNA $^{3}$
}

\section{Özet}

Bu araştırmada, 9 farklı parlak brom (Bromus catharticus Vahl.) hattının Tekirdağ ve Edirne koşullarında bazı morfolojik özelliklerinin ve ot verimlerinin belirlenmesi amaçlanmıştır. Denemeler Tesadüf Blokları Deneme Desenine göre üç tekrarlamalı olarak Tekirdağ Namık Kemal Üniversitesi Ziraat Fakültesi Tarla Bitkileri Bölümü ve Edirne Trakya Tarımsal Araştırma Enstitüsü Müdürlüğü deneme arazilerinde 2015-2016 yılları arasında yürütülmüsşür. Araştırmada morfolojik özellik olarak ana sap uzunluğu, ana sap kalınlığı, boğum arası uzunluk, ana saptaki boğum sayısı, bayrak yaprak eni ve boyu ile yeşil ve kuru ot verimleri tespit edilmiştir. Parlak brom hatlarının ana sap uzunluğu, ana sap kalınlığı, boğum arası uzunluk, ana saptaki boğum sayısı, bayrak yaprak eni ve boyu ile yeşil ve kuru ot verimleri arasında istatistiki olarak önemli farklar ortaya çıkmıştır. Ana sap uzunluğu, Tekirdağ lokasyonunda 72.57-99.05 cm, Edirne lokasyonunda ise $94.36-111.73 \mathrm{~cm}$ arasında belirlenmiştir. Ana sap kalınlığı Tekirdağ lokasyonunda 1.58-2.23 mm, Edirne lokasyonunda 2.57-4.52 mm arasında ölçülmüştür. Boğum arası uzunlukları Tekirdağ lokasyonunda 9.95-13.26 cm, Edirne lokasyonunda 14.09- $22.30 \mathrm{~cm}$ olarak belirlenmiştir. Ana saptaki boğum sayısı Tekirdağ lokasyonunda 3.93-4.67 adet, Edirne lokasyonunda 3.47-4.60 adet arasındadır. Bayrak yaprak boyu Tekirdağ lokasyonunda 23.76-26.40 cm, Edirne lokasyonunda 17.46-26.40 $\mathrm{cm}$ olmuştur. Bayrak yaprak eni ise Tekirdağ lokasyonunda 4.93-8.90 mm, Edirne lokasyonunda 2.84-4.85 mm arasında değişmiştir. Yeşil ot verimi, Tekirdağ lokasyonunda 2.208,57-3.521,27 $\mathrm{kg} \mathrm{da}^{-1}$ olurken, Edirne lokasyonunda ise $2.567,73-4.032,06 \mathrm{~kg} \mathrm{da}^{-1}$ arasında tespit edilmiştir. Kuru ot verimi Tekirdağ lokasyonunda 638.89-956.07 kg da ${ }^{-1}$, Edirne lokasyonunda $739.241 .075,44 \mathrm{~kg} \mathrm{da}^{-1}$ arasında saptanmıştır. En yüksek yeşil ve kuru ot verimleri Edirne lokasyonunda 197848 nolu hatta Tekirdağ lokasyonunda 217583 ve 197848 nolu hatlarda tespit edilmiştir. Sonuç olarak, Türkiye'nin Trakya kesimi koşullarında 197848 ve 217583 nolu parlak brom hatları yüksek yeşil ve kuru ot verimleri ile yeni çeşit adayı olarak geliştirilebilir.

Anahtar kelimeler: Bromus catharticus Vahl., Parlak brom, Kuru ot verimi, Yeşil ot verimi, Lokasyon

\footnotetext{
1*Sorumlu Yazar/Corresponding Author: Ersan Bato, Tekirdağ Namık Kemal Üniversitesi, Fen Bilimleri Enstitüsü, Tarla Bitkileri Anabilim Dalı, Tekirdağ. E-mail:ersanbato20@gmail.com (iD) OrcID: 0000-0002-4169-9116

${ }^{2}$ İlker Nizam, Tekirdağ Namık Kemal Üniversitesi, Fen Bilimleri Enstitüsü, Tarla Bitkileri Anabilim Dalı, Tekirdağ. E-mail:inizam@nku.edu.tr (iD OrcID: 00000001-9295-2719.

${ }^{2}$ Metin Tuna, Tekirdağ Namık Kemal Üniversitesi, Fen Bilimleri Enstitüsü, Tarla Bitkileri Anabilim dalı, Tekirdağ. E-mail:metintuna66@yahoo.com (DD OrcID: 0000-0003-4841-8871.

Atıf/Citation: Bato E., Nizam İ., Tuna M. Parlak Brom (Bromus catharticus Vahl.) Hatlarının Ot Verimi ve Bazı Morfolojik Özelliklerinin Belirlenmesi. Tekirdă̆ Ziraat Fakültesi Dergisi, 18 (1),169-178.

*Bu çalıșma Yüksek Lisans tezinden özetlenmiștir.

CBu çalışma Tekirdağ Namık Kemal Üniversitesi tarafından Creative Commons Lisansı (https://creativecommons.org/licenses/by-nc/4.0/) kapsamında yayınlanmıştır. Tekirdağ 2021
} 


\begin{abstract}
The aim of this research was to determine the forage yield performance and some morphological characteristics of nine different prairie grass (Bromus catharticus Vahl.) line in the conditions of Tekirdağ and Edirne. The experiments was carried out in randomized complete block design with three replications at the experimental areas of Field Crops Department of Agricultural Faculty of Tekirdağ Namık Kemal University and Directorate of Trakya Agricultural Research Institute in 2015-2016 years. Morphological characters such as main stem lenght, main stem thickness, internode lenght, main stem node number, flag leaf width and lenght with hay and fresh yield were investigated in the study. Differences among lenght of main stem, thickness of main stem, internode lenght, node number of main stem, lenght of flag leaf, width of flag leaf, fresh and hay yields of the prairie grass lines were found to be statistically very significant. The lenght of main stem varied between $72.57-99.05 \mathrm{~cm}$ in Tekirdag location and $94.36-111.73 \mathrm{~cm}$ in Edirne location. The thickness of the main stem varied between $1.58-2.33 \mathrm{~mm}$ in Tekirdag location and 2.57-4.52 $\mathrm{mm}$ in Edirne location. Internode lenght varied between $9.95-13.26 \mathrm{~cm}$ in Tekirdag location and 14.09-22.30 cm in Edirne location. The node number of main stem varied between 3.934.67 in Tekirdag location and 3.47-4.60 in Edirne location. Lenght of flag leaf varied between $23.76-26.40 \mathrm{~cm}$ in Tekirdag location and 17.46-26.40 cm in Edirne location. Width of flag leaf varied between 4.93-8.90 $\mathrm{mm}$ in Tekirdag location and 2.84-4.85 mm in Edirne location. Fresh yield of linesvaried between 2.208,57-3.521,27 kg $\mathrm{da}^{-1}$ in Tekirdağ 2.567,73-4.032,06 $\mathrm{kg} \mathrm{da}^{-1}$ in Edirne conditions. Hay yield of lines varied between 638.89-956.07 $\mathrm{kg} \mathrm{da}^{-1}$ in the conditions of Tekirdağ, and 739.24-1.075,44 $\mathrm{kg} \mathrm{da}^{-1}$ in the conditions of Edirne. The highest fresh and hay yield was determined from 197848 line in Edirne location and from 217583 and 197848 lines in the location of Tekirdağ where the research was conducted. Based on the results of this study, prairie grass lines 197848 and 217583 can be suggested for cultivation in the Thrace part of Turkey.
\end{abstract}

Keywords: Bromus catharticus Vahl., Prairie grass, Hay yield, Fresh yield, Location 


\section{Giriș}

Brom cinsinin anavatanı Asya, Avrupa ve Amerika olarak kabul edilmekte olup, çok yıllık ve tek yıllık olmak üzere dünya geneline yayılmış 160 kadar türü bulunmaktadır. Bununla birlikte sadece birkaç tanesinin kültürü yapılmakta ve bunlardan en yaygın olanları; kılçıksız brom (Bromus inermis L.), çayır bromu (Bromus riparius L.), dik brom (Bromus erectus Huds.) ve parlak brom (Bromus catharticus Vahl.)'dur (Tuna ve ark. 2001).

Tarımı yapılan türlerden birisi olan parlak brom değerli bir yem bitkisidir. Poacea familyasından Festucaidea alt familyasından Festuca oymağından bir bitkidir. Genel olarak, Bromus catharticus Vahl olarak adlandırılmakla birlikte, Bromus unioloides H.B.K. ve Bromus wildenowii Kunth olarakta isimlendirilmektedir. Bu türün orijini çayırların ve bozkırların nemli bölgeleridir. Güney Amerika kıtasındaki yayılışı Şili’nin kuzey bölgelerinden Brezilya'nın güneyine ve Uruguay'a kadar uzanır (Rosso ve ark., 2009). Dünyanın 1lıman bölgelerinde kültüre alınmış ve özellikle Arjantin'in Pampeana bölgesinde yaygın bir şekilde yetiştirilmektedir (Hauman, 1917). Uruguay, Paraguay, Şili, Arjantin, Peru, Ekvator, Kolombiya, Bolivya, Brezilya, Venezuela gibi Güney Amerika ülkelerinde yerel bir bitki olarak tarımı yapılmaktadır (Newell, 1973). Güneydoğu Avusturalya'da ve Japonya'da yaygın olarak bulunmakta ve istilacı bir tür olarak kabul edilmektedir (Auld ve ark., 2003).

Parlak brom 30-100 cm kadar boylanabilen, yaprakları yumuşak tüylü, 10-30 cm uzunluğunda ve 3-8 mm genişliğindedir. Salkımlarının boyu 10-40 cm uzunluğunda olup başakçıklar basık 6-12 adet çiçeklidir (Serin ve Tan, 2009). Sonbahar ve kış süresince gelişimini sürdürmekte, yüksek verimini ve lezzetliliğini korumaktadır (Hume 1991 a, Hume 1991 b, Abbott ve ark., 2012). Toprağın eğimli olduğu yol kenarlarında hızla yayılma özelliğine sahiptir (Muzafar ve ark., 2016). Otlatma ve kuru ot üretimi amaciyla yetiştirilmektedir. Yem bitkisi olarak yüksek verimli olmasının yanı sıra, kuraklığa diğer serin mevsim yem bitkilerinden daha yüksek derecede tolerans göstermesi açısından ülkemizin pek çok yerinde başarılı şekilde yetiştirilme olanağına sahip olup, kaba yem sorununun çözümüne katkı sağlayacak olan bir yem bitkisidir. Parlak bromun seyrek biçim ve rotasyonel bir otlatma sisteminde süt sığırları için yoğun olarak kullanılan bir tür olduğunu, kurak veya verimsiz topraklarda otlatma koşulları altında yaz periyodunda ölümler olabileceğini bildirmiştir (Rumball, 1974).

Ülkemiz hayvancılığında karşılaşılan ana sorunlardan biri hayvancılığın ana besin kaynağı olan kaba yemin yeterli düzeylerde üretilememesi sonucu üretim maliyetleri hızla yükselmektedir. Bu sorunun giderilmesi düşük maliyetli ve güvenli yem kaynağı olan çayır mera alanlarının etkin şekilde kullanımı ile mümkün olabilir. Meraların verimlerinin arttırılması da kaba yem açığını giderecek düzeyde değildir. Bu bağlamda verim ve kalite değerinin yüksek olduğu ve ekilecek bölgeye adapte olabilen farklı yem bitkisi türlerine büyük oranda ihtiyaç vardır. Gerek ülke genelinde gerekse bölgesel olarak adapte olabilecek yeni yem bitkisi türleri ile ilgili çalışmaların sayısı hızla artırılmalidir.

Konuyla ilgili yapılan benzer bir araştırmada, Tekirdağ ekolojik koşullarında yetiştirilen bazı parlak brom hatlarında yeşil ot verimi bakımından en yüksek verim 1.biçimde 4.380,00 $\mathrm{kg} \mathrm{da}^{-1}$ ile 284788 nolu hatta, 2. biçimde ise $606.00 \mathrm{~kg} \mathrm{da}^{-1}$ ile ARBR01 nolu hatta belirlenmiştir. Y1llık toplam yeşil ot verimi bakımından ise, $4.793,00 \mathrm{~kg}$ $\mathrm{da}^{-1}$ ile 284788 nolu hatta en yüksek verim tespit edilmiştir. En yüksek kuru ot verimi 1. biçimde $1.614,67 \mathrm{~kg} \mathrm{da}^{-1}$ ile 284788 nolu hatta, 2. biçimde $237.00 \mathrm{~kg} \mathrm{da}^{-1}$ ile 462243 nolu hatta, toplam kuru ot verimi ise $1.761,67 \mathrm{~kg} \mathrm{da}^{-1}$ ile 284788 nolu hatta saptanmıştır. Yeşil ot verimleri 457,00 - 4793,00 kg da-1 arasında, kuru ot verimleri 186,00$1761,67 \mathrm{~kg} \mathrm{da}^{-1}$ arasında değişmiştir (Nizam ve ark., 2017).

Arjantin'de yetiştirilen 3 farklı parlak brom varyetesinin kuru madde verimleri 1989 yılında 493-672 kg da-1, 1990 y1lında 624-716 $\mathrm{kg} \mathrm{da}^{-1}$ olarak belirlenmiş̧tir (Jatimliansky ve ark., 1997).

Runball ve ark. (1972) Yeni Zellanda'da 12 parlak brom hattı üzerinde yaptıkları çalışmalarda en yüksek kuru ot verimini $1220 \mathrm{~kg} \mathrm{da}^{-1}$, en düşük ise $920 \mathrm{~kg} \mathrm{da}^{-1}$ olduğunu bildirmişlerdir. Abbott ve ark. (2012) parlak bromun 13 genotipini ot üretimi amacıyla 3 yıl süreyle yetiştirdikleri araştırmalarında genotip x çevre interaksiyonu istatiksel olarak önemli bulunmuştur. Araştırmacılar farklı çevre koşullarına karşı genotiplerin tepkilerinin farklı olduğunu ve fenotipik farklılığın sıcaklık, yağış ve gün ışı̆̆ı gibi çevresel farklardan ortaya çıktığını belirtmişlerdir. Kullanılan parlak brom genotiplerinin kuru ot verimi en düşük $1344 \mathrm{~kg} \mathrm{da}^{-1}$, en yüksek $2117 \mathrm{~kg} \mathrm{da}^{-1}$, ortalama $1652 \mathrm{~kg} \mathrm{da}^{-1}$ olarak bildirilmiştir. 
Bu çalışmanın amacı, Marmara Bölgesinin Trakya kesiminde parlak bromun adaptasyonunu incelemek ve yeni parlak brom çeşitlerinin geliştirilmesine katkı sağlamaktır.

\section{Materyal ve Metot}

Bu çalışmada materyal olarak kullanılan 9 parlak brom hattı (283204, 316173, ARBR01, 217583, 168564, 197848, 283204, 477984, 634281), Western Regional Plant Introduction Station (Pulmann Washington, ABD) bünyesinde bulunan gen bankasından temin edilmiş 83 aksesyon içinden Tekirdağ Namık Kemal Üniversitesi Ziraat Fakültesi Tarla Bitkileri Bölümü tarafından seleksiyon ıslahı ile geliştirilmiştir.

Denemeler, Tekirdağ İli Tekirdağ Namık Kemal Üniversitesi Ziraat Fakültesi Tarla Bitkileri Bölümü deneme alanı ve Edirne İli Trakya Tarımsal Araştırma Enstitüsü Müdürlüğü deneme alanında yürütülmüştür. Araştırma alanlarının iklim verileri Tablo 1 ve Tablo 2'de gösterilmiştir.

Tablo 1. Tekirdă iline ait meteorolojik veriler

Table 1. Meteorological data of Tekirdag Province

\begin{tabular}{|c|c|c|c|c|c|c|}
\hline \multirow[b]{2}{*}{ Aylar } & \multicolumn{2}{|c|}{ Sicaklık ( $\left.{ }^{\circ} \mathrm{C}\right)$} & \multicolumn{2}{|c|}{ Yağıș (mm) } & \multicolumn{2}{|c|}{ Oransal Nem (\%) } \\
\hline & 2015-2016 & $\begin{array}{l}\text { Uzun } \\
\text { yillar }\end{array}$ & 2015-2016 & $\begin{array}{l}\text { Uzun } \\
\text { yillar }\end{array}$ & 2015-2016 & $\begin{array}{l}\text { Uzun } \\
\text { yillar }\end{array}$ \\
\hline Ekim & 16,4 & 15,7 & 83,7 & 90,0 & 80,1 & 80,5 \\
\hline Kasım & 13,8 & 11,3 & 48,5 & 62,5 & 80,7 & 84,0 \\
\hline Aralık & 7,3 & 7,2 & 0,7 & 82,5 & 79,9 & 83,6 \\
\hline Ocak & 5,6 & 5,2 & 70,7 & 62,1 & 80,0 & 84,0 \\
\hline Şubat & 9,7 & 5,7 & 68,4 & 64,9 & 85,5 & 81,4 \\
\hline Mart & 10,4 & 8,0 & 30,6 & 57,4 & 80,3 & 80,7 \\
\hline Nisan & 15,6 & 12,2 & 22,9 & 41,5 & 72,2 & 78,2 \\
\hline Mayıs & 17,9 & 17,6 & 28,1 & 33,8 & 74,4 & 75,1 \\
\hline Haziran & 23,6 & 22,2 & 35,0 & 35,0 & 72,2 & 72,6 \\
\hline Ortalama/toplam & 13,37 & 11,7 & 388,6 & 529,7 & 78,4 & 80,0 \\
\hline
\end{tabular}

Tekirdağ ilinde Ekim 2015- Haziran 2016 döneminde 388.6 mm yağış düşmüştür (Tablo 1). Bu miktar uzun y1llar ortalamasından oldukça düşüktür. Aynı şekilde oransal nem miktarı da aynı dönemde uzun yıllar ortalamasından aşağıdadır. Sıcaklık ortalamaları ise uzun yıllara göre daha yüksek olarak gerçekleşmiştir. Bu sonuçlar denemenin yürütüldüğü dönemde Tekirdağ ilinde kurak ve sıcak bir yılın geçtiğini göstermektedir. Edirne ilinde ise aynı dönemde toplam yağış $547.8 \mathrm{~mm}$, ortalama sıcaklık $12.6^{\circ} \mathrm{C}$, oransal nem \% 77.2 olarak gerçekleşmiştir (Tablo 2). Tablo 2'de de görüldüğü gibi Edirne ilinde yağış, sıcaklık ve nem miktarları uzun yıllar ortalamasından yüksek olmuştur. Bu verilere göre yetiştirme döneminde sıcak ve yağışılı bir periyodun mevcut olduğu söylenebilir.

Tablo 2. Edirne iline ait meteorolojik veriler

Table 2. Meteorological Data of Edirne Province

\begin{tabular}{lcccccc}
\hline & \multicolumn{2}{c}{${\text { Sıcaklık }\left({ }^{\circ} \mathbf{C}\right)}$} & \multicolumn{2}{c}{ Yağıș (mm) } & \multicolumn{2}{c}{ Nem (\%) } \\
\cline { 2 - 7 } Aylar & $\mathbf{2 0 1 5 - 2 0 1 6}$ & Uzun & $\mathbf{2 0 1 5 - 2 0 1 6}$ & Uzun & $\mathbf{2 0 1 5 - 2 0 1 6}$ & $\begin{array}{c}\text { Uzun } \\
\text { yıllar }\end{array}$ \\
\hline Ekim & 15,6 & 14,2 & 52,6 & 56,7 & 81,7 & 72 \\
Kasım & 13,5 & 9,3 & 26,2 & 68,8 & 81,7 & 80 \\
Aralık & 5,5 & 4,5 & 0,3 & 75,2 & 83,6 & 82 \\
Ocak & 2,8 & 2,0 & 114,8 & 62,9 & 84,5 & 81 \\
Şubat & 9,2 & 5,2 & 91,4 & 50,8 & 85,5 & 77 \\
Mart & 10,2 & 7,1 & 54,8 & 46,2 & 77,5 & 73 \\
Nisan & 15,5 & 12,7 & 116,1 & 49,9 & 66,6 & 68 \\
Mayıs & 17,4 & 17,5 & 81,4 & 49,2 & 71,8 & 67 \\
Haziran & 23,9 & 22,0 & 10,2 & 48,9 & 61,8 & 62 \\
Ortalama/toplam & 12,6 & 10,5 & 547,8 & 508,6 & 77,2 & 73,6 \\
\hline
\end{tabular}


Araştırmanın yürütüldüğü Tekirdağ Namık Kemal Üniversitesi Ziraat Fakültesi Tarla Bitkileri Bölümü ve Edirne İli Trakya Tarımsal Araştırma Enstitüsü Müdürlüğü deneme parsellerinden alınan toprak numuneleri Edirne Ticaret Borsası Laboratuvarı'nda analiz edilmiştir (Tablo 3). Araştırma alanlarının toprakları hafif asit karakterde olup, Edirne'de daha asidik özelliğe sahiptir. Tekirdağ deneme alanında fosfor miktarı yetersiz, Edirne deneme alanında ise yüksek olarak görülmektedir. Deneme alanları kalsiyum, magnezyum, potasyum ve mangan içeriği bakımdan elverişli düzeydedir. Organik madde miktarı her iki deneme alanında da oldukça düşüktür.

Tablo 3. Tekirdăg ve Edirne İlindeki Deneme Alanlarına Ait Toprak Analiz Sonuçları

Table 3. Soil Analysis Results of Experimental Areas in Tekirdag and Edirne Provinces

\begin{tabular}{lcccc}
\hline \multirow{2}{*}{ Toprak özellikleri } & \multicolumn{2}{c}{ Tekirdă } & \multicolumn{2}{c}{ Edirne } \\
\cline { 2 - 5 } & $\mathbf{0 - 2 0 ~ c m}$ & $\mathbf{2 0 - 4 0 ~ c m ~}$ & $\mathbf{0 - 2 0} \mathbf{~ c m}$ & $\mathbf{2 0 - 4 0 ~ c m ~}$ \\
\hline Su ile doymuşluk & 40 & 41 & 40 & 41 \\
pH & 6.10 & 6.35 & 5,9 & 5,8 \\
Kireç (\%) & 0.01 & 0.01 & 0,00 & 0,00 \\
Fosfor (1,39-3,26) (ppm) & 1.2 & 1.1 & 6,2 & 7,7 \\
Kalsiyum (1150-3500) (ppm) & 2800 & 2350 & 1758 & 2313 \\
Magnezyum (160-480) (ppm) & 431 & 382 & 262 & 326 \\
Potasyum (140-370) (ppm) & 179 & 152 & 175 & 234 \\
Mangan (14-50) (ppm) & 24 & 21 & 83 & 89 \\
Çinko (0,7-2,4) (ppm) & 0.25 & 0.38 & 0,85 & 1,1 \\
Organik madde (\%) & 1.02 & 1.10 & 1,25 & 1,28 \\
\hline
\end{tabular}

Parlak brom denemeleri Tekirdağ ilinde 20 Ekim 2015, Edirne ilinde ise 29 Ekim 2015 tarihlerinde tesadüf blokları deneme desenine göre 3 tekrarlamalı olarak kurulmuştur. Her iki lokasyonda da parseller sıra uzunluğu $5 \mathrm{~m}$, sıra aralığ $35 \mathrm{~cm}$ olan 5 sıradan oluşmuştur. Ekim normu $3 \mathrm{~kg} \mathrm{da}^{-1}$, ekim derinliği $2 \mathrm{~cm}$ 'dir. Ekimler elle yapılmıştır. Çıkıştan sonra sıra aralarından çıkan yabancı otlarla el çapası ile mücadele edilmiştir.

Araştırmada yapılan ölçümler, Tarım ve Köyişleri Bakanlığı Tohumluk Tescil ve Sertifikasyon Merkezi Müdürlügü̈nün Brom türleri (Bromus L. species) için yayınlanan Tarımsal Değerleri Ölçme Denemeleri Teknik Talimatına göre yapılmıştır (Anonim, 2001). Bu teknik talimatnameye göre, morfolojik özellikler parlak brom hatlarının çiçeklenme döneminde hasattan önce her parselden rastgele seçilen 10 adet bitki üzerinde belirlenmiştir. Bitki boyu, toprak yüzeyi ile en uçtaki salkımın ucuna kadar olan mesafe metre ile cm olarak ölçülerek belirlenmiştir. Parlak brom bitkilerinin ana sap kalınlığı 2. ve 3. boğum arasının kalınlığının 0,1 mm bölmeli kumpasla mm olarak ölçülmesiyle saptanmıştır. Bitkilerin boğum arası uzunluğu ana sapının 2. ve 3. boğum arasının (cm) ölçülmesiyle belirlenmiştir. Parlak brom bitkilerinin ana saptaki bütün boğumları sayılarak ana saptaki boğum sayısı adet olarak belirtilmiştir. Parlak brom bitkilerinin bayrak yaprak ayasının kına bağlanma noktasından itibaren ucuna kadar olan kısım bayrak yaprak boyu $(\mathrm{cm})$, aynı yaprağın eni de bayrak yaprak eni (mm) olarak ölçülmüştür (Açıkgöz ve Elçi, 1980).

Her parselin kenarlarından 1'er sıra ve sıraların başından ve sonundan olmak üzere 0.5 m'lik kısım biçilerek uzaklaştırılmıştır. Geriye kalan $4.2 \mathrm{~m}^{2}$ alan biçilerek hasat edilmiş ve yeşil ot verimi saptanmıştır. Her parselden elde edilen yeşil ot içerisinden rastgele $0.5 \mathrm{~kg}$ 'lık örnek alınarak kurutma dolabında 48 saat süre ile $78{ }^{0} \mathrm{C}$ 'de kurutma dolabında kurutulmuştur. Daha sonra 24 saat oda ortamında bekletilip tartım yapılmış ve elde edilen kuru ot değerleri dekara verime çevrilmiştir.

Parlak brom hatlarının bazı morfolojik özellikleri ile yeşil ve kuru ot verimlerinin istatiksel analizleri Tesadüf Blokları deneme deseninde 3 tekrarlamalı olarak TARIST istatistik paket programına göre yapılmıştır (Açıkgöz ve ark., 1994). Ortalamaların arasındaki farkların önemliliğinin belirlenmesinde LSD (\% 5) çoklu karşılaştırma testi uygulanmıştır (Düzgüneş ve ark., 1987). 


\section{Araştırma Sonuçları ve Tartışma}

\subsection{Ana Sap Uzunluğu}

Parlak brom hatlarının ana sap uzunlukları arasındaki farklar Tekirdağ lokasyonunda önemli olurken, Edirne lokasyonunda önemsiz olmuştur. Araştırmada kullanılan parlak brom hatlarının Tekirdağ lokasyonundaki ana sap uzunluğu 72.57-99.05 cm arasında değişmiştir (Tablo 4). Yapılan çalışmada Tekirdağ lokasyonunda en yüksek ana sap uzunluğu 99.05 ve $97.92 \mathrm{~cm}$ ile sırasıyla 197848 ve 634281 nolu hatlarda saptanmıştır. En düşük sap uzunluğu ise $72.57 \mathrm{~cm}$ ile ARBR01 nolu hatta belirlenmiştir. Araştırmada kullanılan parlak brom hatlarının Edirne lokasyonundaki ana sap uzunluğu 94.36-111.73 cm arasında değişmiştir. Edirne lokasyonunda en yüksek ana sap uzunluğu $111.73 \mathrm{~cm}$ ile 283204 nolu hatta saptanmıştır. En düşük ana sap uzunluğu ise $94.36 \mathrm{~cm}$ ile ARBR01 nolu hatta belirlenmiştir. En uzun ana sap uzunluğu değerleri, iki lokasyonda farklı hatlarda saptanmıştır. Bununla birlikte en kısa ana sap uzunluğu her iki lokasyonda da ARBR01 nolu hatta belirlenmiştir. Araştırmada bulunan ana sap uzunluğu verileri Muzafar ve ark. (2016)'nın bildirdiği parlak bromda bitki boyunun 85-100 cm arasında olduğu, Serin ve Tan (2009)'1n belirttiği 30-100 cm bitki boyu değerleri ile benzerlik göstermektedir.

\subsection{Ana Sap Kalınlı̆̆}

Ana sap kalınlığı bakımından hatlar arasındaki farklar Tekirdağ lokasyonunda önemsiz olmuş, Edirne lokasyonunda ise önemli bulunmuştur. Araştırmada kullanılan parlak brom hatlarının Tekirdağ lokasyonundaki ana sap kalınlığı 1.58-2.23 mm arasında değişmiştir (Tablo 4). Bu çalışmada Tekirdağ lokasyonunda en yüksek ana sap kalınlığı 2.23 mm ile 217583 nolu hatta saptanmıştır. En düşük ana sap kalınlığ ise $1.58 \mathrm{~mm}$ ile 197848 nolu hatta belirlenmiştir. Parlak brom hatlarının Edirne lokasyonundaki ana sap kalınlığı 2.57-4.52 mm arasında değişmiştir. Edirne lokasyonunda en yüksek ana sap kalınlığı $4.52 \mathrm{~mm}$ ile 283204 nolu hatta saptanmıştır. En düşük ana sap kalınlığı ise 2.57 mm ile 477984 nolu hatta belirlenmiştir. Parlak brom hatlarının ana sap kalınlıkları lokasyonlar arasında farklı olarak ortaya çıkmıştır. Tekirdağ lokasyonunda Edirne lokasyonuna göre daha kalın saplar meydana gelmiştir. Farklılık hatlar arasında da görülmektedir. İki lokasyonda da en kalın ve en ince sapa sahip bitkiler farklı olmuştur. Buna göre, parlak brom hatlarının sap kalınlıklarının çevresel koşullardan etkilendiği ve bu etkinin hatlar arasında farklı olduğu söylenebilir.

Tablo 4. Parlak bromda ana sap uzunluğu, ana sap kalınlı̆̆ı, boğum arası uzunluk ve boğum sayısına ait ortalama değerler ve önemlilik gurupları

Table 4. Average values and significance groups of main stem lenght, main stem thickness, internod length, and node number in prairie grass

\begin{tabular}{|c|c|c|c|c|c|c|c|c|}
\hline \multirow[t]{2}{*}{ Hat No } & \multicolumn{2}{|c|}{$\begin{array}{l}\text { Ana sap uzunluğu } \\
\text { main stem lenght } \\
(\mathbf{c m})\end{array}$} & \multicolumn{2}{|c|}{$\begin{array}{c}\text { Ana sap kalınlığı } \\
\text { main stem thickness } \\
(\mathbf{m m})\end{array}$} & \multicolumn{2}{|c|}{$\begin{array}{c}\text { Boğum arası uzunluk } \\
\text { internod length } \\
(\mathbf{c m})\end{array}$} & \multicolumn{2}{|c|}{$\begin{array}{l}\text { Boğum sayısı } \\
\text { node number } \\
\text { (adet) }\end{array}$} \\
\hline & Tekirdağ & Edirne & Tekirdağ & Edirne & Tekirdağ & Edirne & Tekirdağ & Edirne \\
\hline 283204 & $84.79 \mathrm{~b}$ & 105.93 & 2.07 & $4.52 \mathrm{a}$ & $11.40 \mathrm{~b}$ & 14.09 & $4.40 \mathrm{abc}$ & 4.60 \\
\hline 168564 & $75.42 \mathrm{~cd}$ & 97.80 & 1.77 & $3.77 \mathrm{abc}$ & $9.95 \mathrm{c}$ & 16.65 & $4.63 \mathrm{a}$ & 4.13 \\
\hline 634281 & $97.92 \mathrm{a}$ & 106.93 & 1.85 & $3.33 \mathrm{bcd}$ & $13.11 \mathrm{a}$ & 16.01 & $4.57 \mathrm{ab}$ & 3.80 \\
\hline 477984 & $78.93 \mathrm{bcd}$ & 104.40 & 1.69 & $2.57 \mathrm{~d}$ & $10.95 b c$ & 22.30 & $4.07 \mathrm{bc}$ & 3.47 \\
\hline 197848 & $99.05 \mathrm{a}$ & 99.73 & 1.58 & $3.44 \mathrm{bcd}$ & $13.26 \mathrm{a}$ & 15.41 & $4.67 \mathrm{a}$ & 3.80 \\
\hline 316173 & $76.36 \mathrm{~cd}$ & 94.53 & 1.68 & $4.21 \mathrm{ab}$ & $10.13 b c$ & 14.81 & $4.57 \mathrm{ab}$ & 4.40 \\
\hline 283204 & $80.04 \mathrm{bc}$ & 111.73 & 1.81 & $4.21 \mathrm{ab}$ & $10.53 \mathrm{bc}$ & 14.83 & $4.00 \mathrm{c}$ & 4.33 \\
\hline ARBR01 & $72.57 \mathrm{~d}$ & 94.36 & 1.59 & $2.82 \mathrm{ab}$ & $10.02 b c$ & 19.59 & $3.93 \mathrm{c}$ & 3.53 \\
\hline 217583 & 80.86 bc & 105.27 & 2.23 & $3.91 \mathrm{~cd}$ & $11.13 \mathrm{bc}$ & 17.23 & $4.17 \mathrm{abc}$ & 4.20 \\
\hline LSD \%5 & 7.430 & önemsiz & önemsiz & 1.066 & 1.431 & önemsiz & 0.535 & önemsiz \\
\hline
\end{tabular}




\subsection{Boğum Arası Uzunluk}

Parlak brom hatlarının ana sapında ölçülen boğum arası uzunlukları bakımından farklar Tekirdağ lokasyonunda önemli olurken, Edirne lokasyonunda önemsiz olarak saptanmıştır. Yapılan çalışmada Tekirdağ lokasyonundaki boğum arası uzunlukları $9.95-13.26 \mathrm{~cm}$ arasında değişmiştir (Tablo 4). Tekirdağ lokasyonunda en yüksek boğum arası uzunluk 13.26 ve $13.11 \mathrm{~cm}$ ile sırasıyla 197848 ve 634281 nolu hatlarda saptanmıştır. En düşük boğum arası uzunluk ise $9.95 \mathrm{~cm}$ ile 168564 nolu hatta belirlenmiştir. Edirne lokasyonundaki boğum arası uzunlukları 14.09 $22.30 \mathrm{~cm}$ arasında değişmiştir. Edirne lokasyonunda en yüksek boğum arası uzunluğu $22.30 \mathrm{~cm}$ ile 477984 nolu hatta saptanmıştır. En düşük boğum arası uzunluk ise $14.09 \mathrm{~cm}$ ile 283204 nolu hatta belirlenmiştir. Parlak brom hatlarının boğum arası uzunluğu Tekirdağ lokasyonunda $(9.95-13.26 \mathrm{~cm})$ Edirne lokasyonuna göre (14.09-22.30 $\mathrm{cm})$ daha kısa olarak saptanmıştır. Edirne lokasyonunda boğum arası uzunluğun daha fazla olması bitki boylarının daha yüksek olmasıyla ilişkilidir. Bitki boyunun artışı boğum arası uzunluğun artmasına olumlu etkide bulunmuştur.

\subsection{Ana Saptaki Bŏğm Sayısı}

Ana saptaki boğum sayıları arasındaki farklar Tekirdağ lokasyonunda önemli, Edirne lokasyonunda önemsiz olmuştur. Tekirdağ koşullarında yetiştirilen parlak brom hatlarının ana saplarındaki boğum sayısı 3.93-4.67 adet arasında değişmiştir (Tablo 4). Tekirdağ lokasyonunda en yüksek ana saptaki boğum sayısı 4.67 ve 4.63 adet ile sırasıyla 197848 ve 168564 nolu hatlarda saptanmıştır. En düşük ana saptaki boğum sayısı ise 3.93 adet ile ARBR01 nolu hatta belirlenmiştir. Edirne koşullarında yetiştirilen hatların ana saptaki boğum sayıs1 3.47-4.60 adet arasında değişmiştir. Edirne lokasyonunda en yüksek ana saptaki boğum sayısı 4.60 adet ile 283204 nolu hatta, en düşük ise 3.47 adet ile 477984 nolu hatta belirlenmiştir. Ana saptaki boğum sayıları iki lokasyon arasında incelendiğinde Tekirdağ (3.93-4.67 adet) ve Edirne (3.47-4.60) lokasyonları bakımından belirgin bir fark olmadığ1 görülmektedir. Bu noktadan yola çıkarak, parlak bromda ana saptaki boğum sayısının çevre koşullarından genel olarak fazla etkilenmediği sonucuna ulaşılabilir. Bununla birlikte, hat düzeyinde incelendiğinde bazı hatlarda iki lokasyon arasında boğum sayıları arasında farkların yüksek olduğu görülmektedir. Örneğin, 197848 nolu hatta Tekirdağ lokasyonunda 4.67 adet olan boğum sayısı, Edirne lokasyonunda 3.80 adet olarak ölçülmüştür.

\subsection{Bayrak Yaprak Boyu}

Bayrak yaprak boyları arasındaki fark her iki lokasyonda da önemsiz olmuştur. Parlak brom hatlarının Tekirdağ lokasyonunda ölçülen bayrak yaprak boyu 23.76-26.40 cm arasında değişmiştir (Tablo 5). Tekirdağ lokasyonunda en yüksek bayrak yaprak boyu $26.40 \mathrm{~cm}$ ile 217583 nolu hatta saptanmıştır. En düşük bayrak yaprak boyu ise $23.76 \mathrm{~cm}$ ile 477984 nolu hatta belirlenmiştir. Edirne lokasyonundaki bayrak yaprak boyu $17.46-26.40 \mathrm{~cm}$ arasında değişmiştir. Edirne lokasyonunda en yüksek bayrak yaprağı boyu $26.40 \mathrm{~cm}$ ile 283204 nolu hatta saptanmıştır. En düşük bayrak yaprak boyu ise $17.46 \mathrm{~cm}$ ile ARBR01 nolu hatta belirlenmiştir. Her iki lokasyonda bayrak yaprağ 1 boyu değerleri birbirine oldukça yakındır. Araştırmada tespit edilen bayrak yaprak boyu değerleri Rosso ve ark. (2009)'nın 22.2-38.8 cm, Muzafar ve ark. (2016)'nın 23-28 cm, Serin ve Tan (2009)'ın 10-30 cm, Aulicino ve Arturi (2008)'nin 16.29-31.12 cm olarak bildirdiği bayrak yaprak boyu değerleri ile benzerlik göstermektedir.

\subsection{Bayrak Yaprak Eni}

Parlak brom hatlarının bayrak yaprak eni her iki lokasyonda da istatistiksel olarak önemli farklara sahip olmuştur. Tekirdağ lokasyonunda parlak brom hatlarının bayrak yaprak eni 4.93-8.90 mm arasında değişmiştir (Tablo 5). Tekirdağ lokasyonunda en yüksek bayrak yaprak eni 8.90, 8.30 ve $8.20 \mathrm{~mm}$ ile sirasiyla 217583, 283204 ve 168564 nolu hatlarda saptanmıştır. En düşük bayrak yaprak eni ise $4.93 \mathrm{~mm}$ ile 197848 nolu hatta belirlenmiştir. Edirne lokasyonundaki bayrak yaprak eni 2.84-4.85 mm arasında değişmiştir. Edirne lokasyonunda en yüksek bayrak yaprağı eni 4.85, 4.78, 4.76, 4.60 ve $4.49 \mathrm{~mm}$ ile sirasiyla 217583, 283204, 316173, 283204 ve 168564 nolu hatlarda saptanmıştır. En düşük bayrak yaprak eni ise $2.84 \mathrm{~mm}$ ile 477984 nolu hatta belirlenmiştir. Bayrak yaprağı eni bakımından iki lokasyon ele alındığında, Tekirdağ lokasyonunda bayrak yaprak eni 4.93-8.90 mm, Edirne lokasyonunda 2.84-4.85 mm arasında olduğu görülmektedir. Tekirdağ lokasyonunda yapraklar daha iyi gelişme göstermişlerdir. Araştırmada ölçülen bayrak yaprak eni bulguları Muzafar ve ark. (2016)'nın 5-8 mm, Serin ve Tan (2009)'ın 3-8 mm değerleri ile benzerken, Rosso ve ark. (2009)'nın 6-13 mm değerlerinden daha düşük olarak saptanmıştır. 
Bato \& Nizam \& Tuna Parlak brom (Bromus catharticus Vahl.) hatlarının ot verimi ve bazı morfolojik özelliklerinin belirlenmesi

Tablo 5. Parlak bromda bayrak yaprak boyu, bayrak yaprak eni, yeşil ot verimi ve kuru ot verimine ait ortalama değerler ve önemlilik guruplart

Table 5. Average values and significance groups of flag leaf lenght, flag leaf width, fresh yield, and hay yield in prairie grass

\begin{tabular}{|c|c|c|c|c|c|c|c|c|}
\hline \multirow[t]{2}{*}{ Hat No } & \multicolumn{2}{|c|}{$\begin{array}{l}\text { Bayrak yaprak } \\
\text { boyu } \\
\text { flag leaf lenght } \\
(\mathrm{cm})\end{array}$} & \multicolumn{2}{|c|}{$\begin{array}{c}\text { Bayrak yaprak } \\
\text { eni } \\
\text { flag leaf width } \\
(\mathrm{mm})\end{array}$} & \multicolumn{2}{|c|}{$\begin{array}{l}\text { Yeşil ot verimi } \\
\text { fresh yield } \\
\quad\left(\mathrm{kg} \mathrm{da}^{-1}\right)\end{array}$} & \multicolumn{2}{|c|}{$\begin{array}{l}\text { Kuru ot verimi } \\
\text { hay yield } \\
\left(\mathrm{kg} \mathrm{da}^{-1}\right)\end{array}$} \\
\hline & $\begin{array}{c}\text { Tekirda } \\
\breve{\mathbf{g}}\end{array}$ & Edirne & $\begin{array}{c}\text { Tekirda } \\
\breve{\mathbf{g}}\end{array}$ & $\begin{array}{c}\text { Edirn } \\
\mathrm{e}\end{array}$ & Tekirdağ & Edirne & Tekirdağ & Edirne \\
\hline 283204 & 26.33 & 22.99 & $8.30 \mathrm{a}$ & $4.78 \mathrm{a}$ & $\begin{array}{l}3.252,72 \mathrm{a} \\
\mathrm{b}\end{array}$ & $3.256,53 \mathrm{bc}$ & $878.83 \mathrm{ab}$ & $\begin{array}{l}869.70 b c \\
d\end{array}$ \\
\hline 168564 & 24.99 & 25.57 & $8.20 \mathrm{a}$ & $4.49 \mathrm{a}$ & $\begin{array}{l}3.173,02 \mathrm{a} \\
\mathrm{b}\end{array}$ & $2.926,14 \mathrm{~cd}$ & $\begin{array}{l}807.33 \text { a- } \\
d\end{array}$ & 740.59 e \\
\hline 634281 & 24.76 & 24.65 & $6.83 \mathrm{~b}$ & $\begin{array}{l}3.92 \\
a b\end{array}$ & $\begin{array}{l}3.255,87 \mathrm{a} \\
\mathrm{b}\end{array}$ & $3.375,03 \mathrm{bc}$ & $863.17 \mathrm{ab}$ & $885.98 b c$ \\
\hline 477984 & 23.76 & 22.27 & $6.93 \mathrm{~b}$ & $2.84 \mathrm{~b}$ & $2.208,57 \mathrm{c}$ & $2.567,73 \mathrm{~d}$ & $663.80 \mathrm{~cd}$ & 739.24 e \\
\hline 197848 & 24.63 & 23.63 & $4.93 \mathrm{~d}$ & $\begin{array}{l}4.00 \\
a b\end{array}$ & $\begin{array}{l}3.381,90 a \\
b\end{array}$ & $4.032,06 \mathrm{a}$ & $936.61 \mathrm{a}$ & $1.075,44 \mathrm{a}$ \\
\hline 316173 & 24.12 & 25.26 & $6.37 \mathrm{bc}$ & $4.76 \mathrm{a}$ & $\begin{array}{l}2.664,76 b \\
c\end{array}$ & $\begin{array}{l}3.180,74 b c \\
d\end{array}$ & $638.89 \mathrm{~d}$ & $769.22 \mathrm{de}$ \\
\hline 283204 & 25.90 & 26.40 & $5.43 \mathrm{~cd}$ & $4.60 \mathrm{a}$ & $\begin{array}{l}3.150,48 \mathrm{a} \\
\mathrm{b}\end{array}$ & $3.461,06 \mathrm{abc}$ & $\begin{array}{l}823.95 \text { a- } \\
d\end{array}$ & $882.13 b c$ \\
\hline $\begin{array}{c}\text { ARBR0 } \\
1\end{array}$ & 24.23 & 17.46 & $5.80 \mathrm{bcd}$ & $\begin{array}{l}3.64 \\
a b\end{array}$ & $\begin{array}{l}2.708 .57 b \\
c\end{array}$ & $3.273,44 \mathrm{bc}$ & $\begin{array}{l}686.37 \mathrm{bc} \\
\mathrm{d}\end{array}$ & 814.64 cde \\
\hline 217583 & 26.40 & 26.37 & $8.90 \mathrm{a}$ & $4.85 \mathrm{a}$ & $3.521,27 \mathrm{a}$ & $3.720,21 \mathrm{ab}$ & $956.07 \mathrm{a}$ & $928.16 \mathrm{~b}$ \\
\hline LSD\%5 & önemsiz & $\begin{array}{l}\text { önemsi } \\
\mathrm{z}\end{array}$ & 1.203 & 1.229 & 211.726 & 620.635 & 758.612 & 103.809 \\
\hline
\end{tabular}

\subsection{Yeşil Ot Verimi}

Yeşil ot verimleri arasında her iki lokasyonda da önemli farklar meydana gelmiştir. Parlak brom hatlarının Tekirdağ lokasyonundaki yeşil ot verimleri 2.208,57-3.521,27 kg da-1 arasında değişmiştir (Tablo 5). Tekirdağ lokasyonunda en yüksek yeşil ot verimi $3.521,27 \mathrm{~kg} \mathrm{da}^{-1}$ ile 217583 nolu hatta saptanmıştır. En düşük yeşil ot verimi ise $2.208,57 \mathrm{~kg} \mathrm{da}^{-1}$ ile 477984 nolu hatta belirlenmiştir. Parlak brom hatlarının Edirne lokasyonundaki yeşil ot verimleri 2.567,73-4.032,06 $\mathrm{kg} \mathrm{da}^{-1}$ arasında değişmiştir. Edirne lokasyonunda en yüksek yeşil ot verimi $4.032,06 \mathrm{~kg} \mathrm{da}^{-1}$ ile 197848 nolu hatta saptanmıştır. En düşük yeşil ot verimi ise $2.567,73 \mathrm{~kg} \mathrm{da}^{-1}$ ile 477984 nolu hatta ortaya çıkmıştır. Tekirdağ lokasyonunda yeşil ot verimleri $2.208,57-3.521,27 \mathrm{~kg} \mathrm{da}^{-1}$, Edirne lokasyonunda 2.567,73-4.032,06 kg da ${ }^{-1}$ arasında olduğu görülmektedir. Parlak brom hatlarının yeşil ot verimleri Edirne lokasyonunda nispeten daha yüksek olarak gerçekleşmiştir. Parlak brom hatlarının yeşil ot verimi bakımından en iyi performansı Tekirdağ lokasyonunda 217583 nolu hat, Edirne lokasyonunda 197848 nolu hat göstermiştir. Araştırmada belirlenen parlak brom hatlarının yeşil ot verimi değerlerinin Nizam ve ark. (2017)'nın bildirdiği 457.0-4.793,00 $\mathrm{kg} \mathrm{da}^{-1}$ yeşil ot verimi değerleri ile benzer olduğu tespit edilmiştir.

\subsection{Kuru Ot Verimi}

Parlak brom hatlarının kuru ot verimleri arasındaki farklar her iki lokasyonda da istatistiksel olarak önemli bulunmuştur. Araştırmada kullanılan parlak brom hatlarının Tekirdağ lokasyonundaki kuru ot verimleri 638.89$956.07 \mathrm{~kg} \mathrm{da}^{-1}$ arasında değişmiştir (Tablo 5). Tekirdağ lokasyonunda en yüksek kuru ot verimi 956.07 ve 936.61 $\mathrm{kg} \mathrm{da}^{-1}$ ile sırasıyla 217583 ve 197848 nolu hatlarda saptanmıştır. En düşük kuru ot verimi ise $638.89 \mathrm{~kg} \mathrm{da}^{-1}$ ile 9 nolu hatta ortaya çıkmıştır. Parlak brom hatlarının Edirne lokasyonundaki kuru ot verimleri 739.24-1.075,44 kg $\mathrm{da}^{-1}$ arasında değişmiştir. 
Edirne lokasyonunda en yüksek kuru ot verimi 1.075,44 kg da-1 ile 197848 nolu hatta saptanmıştır. En düşük kuru ot verimi ise 739.24 ve $740.59 \mathrm{~kg} \mathrm{da}^{-1}$ ile sirasıyla 168564 ve 477984 nolu hatlarda ortaya çıkmıştır. Kuru ot verimi bakımından iki lokasyon kıyaslandığında, Tekirdağ lokasyonunda kuru ot verimi 638.89-956.07 kg da-1, Edirne lokasyonunda 739.24-1.075,44 kg da-1 arasında olduğu görülmektedir. Parlak brom hatlarının Edirne koşullarında kuru ot verimleri arasında daha büyük bir fark olduğu, Tekirdağ lokasyonunda hatlar arasında farkların az olduğu görülmektedir. Araştırmada elde edilen kuru ot verimi bulguları Jatimliansky ve ark. (1997) ile Nizam ve ark. (2017)'nın kuru ot verimleri ile benzerlikler göstermektedir. Bulgularımız, Rumball ve ark. (1972)'nın kuru ot verimlerinden düşük, Abbott ve ark. (2012)'nın verimlerinden ise daha yüksek olmuştur.

\section{Sonuç}

Türkiye'nin Marmara Bölgesinin Trakya kesiminin iki farklı lokasyonunda 9 parlak brom hattı yetiştirilmiş ve türün bölge koşullarına adapte olduğu görülmüştür. Yapılan ölçümler sonucunda parlak brom hatları arasında morfolojik ve verim olarak önemli farklar saptanmıştır. Ekolojik olarak farklı olan iki çevre koşulunda hatların performansları da farklılıklar göstermiştir. Tekirdağ koşullarında hatlar arasında ana sap uzunluğu, boğum arası uzunluk, boğum sayısı, bayrak yaprak eni, yeşil ot verimi ve kuru ot verimi bakımından farklar saptanırken, Edirne koşullarında ana sap kalınlığı, bayrak yaprak eni, yeşil ot verimi ve kuru ot verimi bakımından farklar önemli bulunmuştur.

Edirne lokasyonda parlak brom hatlarının ana sap uzunluğu daha uzun, saplar ince ve ana saptaki boğum araları daha uzun olmuştur. Edirne'de mevsimin yağışlı geçmesi daha fazla kardeş oluşumu ve vejetatif gelişmeyi teşvik etmiştir. Kardeş sayısı ölçülmemesine rağmen bu durum gözlemlerde saptanmıştır. Bitki boyunun uzaması ve kardeş sayısının artışı sapların ince kalmasına neden olmuştur. Tekirdağ lokasyonunda ise yapraklar daha iyi gelişme göstermiştir.

Yeşil ve kuru ot verimleri arasında her iki lokasyonda da istatistiki olarak 0,01 önemlilik seviyesinde farklar saptanmıştır. Yeşil ot verimi Tekirdağ şartlarında 2208,5-3521,27 kg da ${ }^{-1}$ arasında olurken, Edirne şartlarında ise 2567,73-4032,06 kg da-1 arasında olmuştur. Kuru ot verimi ise Tekirdağ koşullarında 638,89-956,07 kg da-1 arasında değişiklik gösterirken, Edirne şartlarında 739,24-1075,44 $\mathrm{kg} \mathrm{da}^{-1}$ arasında tespit edilmiştir.

Sonuç olarak, Türkiye'nin Trakya kesimi koşullarında parlak brom bitkisinin alternatif bir yem bitkisi olarak yetiştirilme olanağı bulunmaktadır. Araştırmanın yürütüldüğü iki lokasyonda da 197848 ve 217583 nolu hatlar en yüksek yeşil ve kuru ot verimlerine ulaşarak çeşit adayı olarak geliştirilmeye uygun bulunmuştur. 


\section{Kaynakça}

Abbott, L., Fillipinni, S., Delfino, H., Pistorale, S. (2012). Stability Analysis of Forage Production in Bromus Catharticus (Prairie Grass) Using Three Methodologies. Cien. Inv. Agr. 39 (2): 331-338.

Açıkgöz, E., Elçi, Ş. (1980). Adi Otlak Ayrı̆̆ında (Agropyron cristatum L. Gaertn) Bazı Morfolojik Ve Tarımsal Özellikler İle Çiçek Biyolojisi Üzerinde Araştırmalar. A.Ü. Ziraat Fakültesi Diploma Sonrası Yüksekokulu Doktora Tez Özetleri S: 116-130, Ankara.

Açıkgöz, N., Akbaş, M. E., Moghaddam A., Özcan K. (1994). PC'ler için Veri Tabanı Esaslı Türkçe İstatistik Paketi: TARİST. Türkiye 1. Tarla Bitkileri Kongresi, s:264-267, 24-28 Eylül, İzmir/Türkiye.

Anonim, (2001). Brom Türleri (Bromus L. species). Tarımsal Değerleri Ölçme Denemeleri Teknik Talimatı. Tarım ve Köyişleri Bakanlığı Tohumluk Tescil ve Sertifikasyon Merkezi Müdürlüğü, Ankara.

Auld, B., Morita, H., Nishida, T., Ito, M., Micheal, P. (2003). Shared Exotica: Plant Invasions of Japan and South Eastern Australia. Cunninghamia. 8: 147-152. https://d1nu2wha2fqaui.cloudfront.net// RoyalBotanicGarden/media/RBG/science/Cunninghamia/Volume\%208\%20-\%202003/Volume-8(1) 2003-Cun8Aul147-152.pdf

Aulicino, M. B., Arturi, M. J. (2008). Regional Variation in Argentinean Populations of Bromus catharticus (Poaceae) as Measured By Morphological Divergence Associated With Environmental Conditions. Anales del Jardin Botanico de Madrid , 65 (1): $135-147$ enero-junio.

Düzgüneş, O., Kesici, T., Kavuncu, O., Gürbüz, F. (1987). Araştırma ve Deneme Metodları (İstatistiksel Metodlar-II ). Ankara Üniv. Zir. Fak. Yayınları No:1021, Ders kitabı seri No:295, Ankara

Hauman, L. (1917). Notes floristiques. Quelques cryptogame, gymnospermes et monocotyledones de 1' Argentine. Anales Museo Nac His Nat, 28: 391-443.

Hume, D. E. (1991 a ). Effect of Cutting on Preduction and Tillering In Prairie Grass Compared With Two Ryegrass Species. 1. Vegetative Plants Annals of Botany, 68

Hume, D. E. (1991 b). Effect Of Cutting on Preduction and Tillering İn Prairie Grass Compared With Two Ryegrass Species. 2.Reproductive Plants Annals of Botany, 68.

Jatimliansky, J., Gimenez, D O., Bujan, A. (1997). Herbage Yield, Tiller Number and Root System Activity After Defoliation of Prairie Grass (Bromus catharticus Vahl.). Grass and Forage Science, 52: 52-62.

Muzafar, I., Khuroo, A. A., Mehraj, G., Hamid, M., Rashid, I. (2016). Bromus catharticus Vahl. (Poaceae): A New Plant Record for Kashmir Himalaya, India. Check List 12(2):1875.

Newell, L. C. (1973). Smooth Bromegrass; p. 254, in: M.E. Heath, D.S. Metcalfe and R.F. Barnes (eds.). Forages: the science of grassland agriculture. Ames, Iowa: Iowa State University Press.

Nizam, İ., Teykin E E., Tuna M. (2017). Tekirdağ Koşullarında Bazı Parlak Brom (Bromus catharticus Vahl.) Hatlarının Ot Verimlerinin Belirlenmesi. 12. Tarla Bitkileri Kongresi, Elektronik Kongre Kitab1, s:244-248, Kahramanmaraş.

Rosso, B., Pagano, E., Rimieri, P., Rios, R. (2009). Characteristics of Bromus catharticus Vahl. (Poaceae) Natural Population Collected In The Central Area of Argentina. Sci.Agric (Piracicaba, Braz .), 66 (2): 276-279.

Rumball, W., Butler G W., Jackman R H. (1972). Variation In Nitrogen and Mineral Composition In Populations of Prairie Grass (Bromus unioloides H.B.K). New Zealand Journal of Agricultural Research, 15 (1):33-42.

Rumball, W. (1974) 'Grasslands Matua' prairie Grass (Bromus catharticus Vahl.). New Zelland Journal of Experimental Agriculture, 2:1-5.

Serin, Y., Tan, M. (2009). Bromus sp L. Yembitkileri Buğdaygil ve Diğer Familyalardan Yembitkileri, Cilt III. Editörler: R. Avcığlu, R. Hatipoğlu, Y. Karadağ. Emre Basımevi- İzmir, ISBN: 978-605- 60864-1-0(3.c)

Tuna, M., Vogel, K. P., Arumuganathan K., Gill K S., 2001. DNA Content and Ploidy Determination of Bromegrass Germplasm Accessions By Flow Cytometry. Crop Science, 41:1629-1634. 